\title{
Inclusion Complexes of Sunscreen Agents with $\beta$-Cyclodextrin: Spectroscopic and Molecular Modeling Studies
}

\author{
Nathir A. F. Al-Rawashdeh, ${ }^{1,2}$ Khaled S. Al-Sadeh, ${ }^{2}$ and Mohammad Bassam Al-Bitar ${ }^{3}$ \\ ${ }^{1}$ Department of Chemistry, College of Science, United Arab Emirates University, P.O. Box 15551, Al Ain, Abu Dhabi, UAE \\ ${ }^{2}$ Department of Applied Chemical Sciences, Jordan University of Science and Technology, P.O. Box 3030, Irbid 22110, Jordan \\ ${ }^{3}$ Alfa Chemical Manufacturing Co., P.O. Box 1880, Amman 11118, Jordan
}

Correspondence should be addressed to Nathir A. F. Al-Rawashdeh; nathir@uaeu.ac.ae

Received 21 January 2013; Revised 1 April 2013; Accepted 12 April 2013

Academic Editor: Alaa Eldin Salem

Copyright (C) 2013 Nathir A. F. Al-Rawashdeh et al. This is an open access article distributed under the Creative Commons Attribution License, which permits unrestricted use, distribution, and reproduction in any medium, provided the original work is properly cited.

\begin{abstract}
The inclusion complexes of selected sunscreen agents, namely, oxybenzone (Oxy), octocrylene (Oct), and ethylhexylmethoxycinnamate (Cin) with $\beta$-cyclodextrin $(\beta$-CD) were studied by UV-Vis spectroscopy, differential scanning calorimetry (DSC), ${ }^{13} \mathrm{C}$ NMR techniques, and molecular mechanics (MM) calculations and modeling. Molecular modeling (MM) study of the entire process of the formation of $1: 1$ stoichiometry sunscreen agent $/ \beta$-cyclodextrin structures has been used to contribute to the understanding and rationalization of the experimental results. Molecular mechanics calculations, together with ${ }^{13} \mathrm{C}$ NMR measurements, for the complex with $\beta$-CD have been used to describe details of the structural, energetic, and dynamic features of host-guest complex. Accurate structures of CD inclusion complexes have been derived from molecular mechanics (MM) calculations and modeling. The photodegradation reaction of the sunscreen agents' molecules in lotion was explored using UV-Vis spectroscopy. It has been demonstrated that the photostability of these selected sunscreen agents has been enhanced upon forming inclusion complexes with $\beta$-CD in lotion. The results of this study demonstrate that $\beta$-CD can be utilized as photostabilizer additive for enhancing the photostability of the selected sunscreen agents' molecules.
\end{abstract}

\section{Introduction}

Cyclodextrins (CDs) are cyclic oligosaccharides composed of glucopyranose units linked together by oxygen bridges at the 1 and 4 positions ( $\alpha, 1,4$-glycoside bonds) [1]. This class of organized media possesses a hydrophilic exterior and a hydrophobic cavity due to $\mathrm{C}^{3} \mathrm{H}, \mathrm{C}^{5} \mathrm{H}$, and $\mathrm{C}^{6} \mathrm{H}$ hydrogens and $\mathrm{O}^{4}$ ether oxygen which enables the $\mathrm{CDs}$ to extract a variety of organic guest molecules of appropriate size and hydrophobicity from the bulk aqueous solution [2-4]. The most familiar members are $\alpha$-, $\beta$-, and $\gamma$-CDs consisting of six, seven, and eight glucose units, respectively.

Complexation of various compounds with CDs leads to an enhancement in some of the characteristics of the guest molecules, such as thermalstability and photostability, bioavailability, membrane permeability, and solubility [5]. Thus, CDs and their derivatives have been employed in a variety of fields such as catalysis, electrochemical analysis, pharmaceutical and food industries [6-12], separation sciences [13-18], and biotechnology [19, 20]. In cosmetics the use of CDs is still having a shortage in the literature information in comparison with other areas, whereas most publications are patents. It is noteworthy to mention that significant alterations in the physicochemical properties of the included molecule have been observed upon forming the inclusion complex with CDs [1-3, 12, 21].

CDs encapsulation of a drug will affect many of the drug's physicochemical properties without affecting its intrinsic pharmacologic properties [4]. One of the most unique properties of CDs is their ability to enhance dermal and transdermal drug delivery without affecting the skin barrier, the stratum corneum. The skin has a much lower affinity for hydrophilic CD molecules, and therefore they remain in the aqueous vehicle system [12].

CDs have been used for a variety of reasons in cosmetic preparations, such as reducing the odor in mercaptan systems, improving the stability of hair dyes, controlling volatility, and as an active ingredient in antiacne treatments 
<smiles>COc1ccc(C(=O)c2ccccc2)c(O)c1</smiles>

Oxybenzone (Oxy)

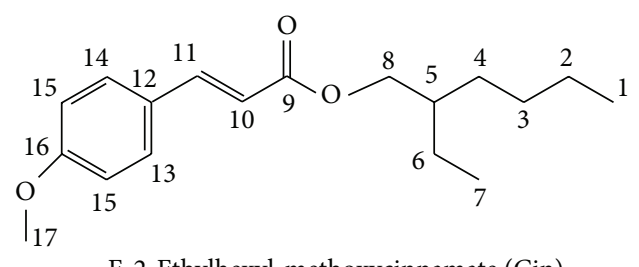

E-2-Ethylhexyl-methoxycinnamate (Cin)

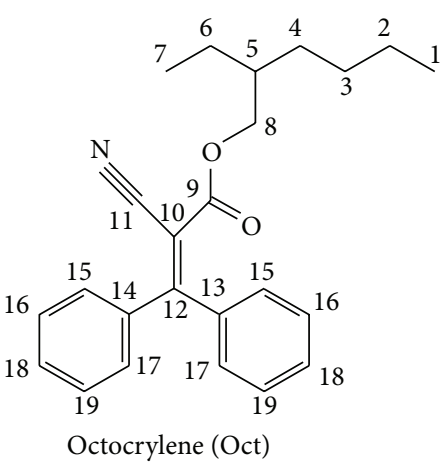

Octocrylene (Oct)

Scheme 1: Chemical structures of oxybenzone (Oxy), octocrylene (Oct), and ethylhexyl methoxycinnamate (Cin).

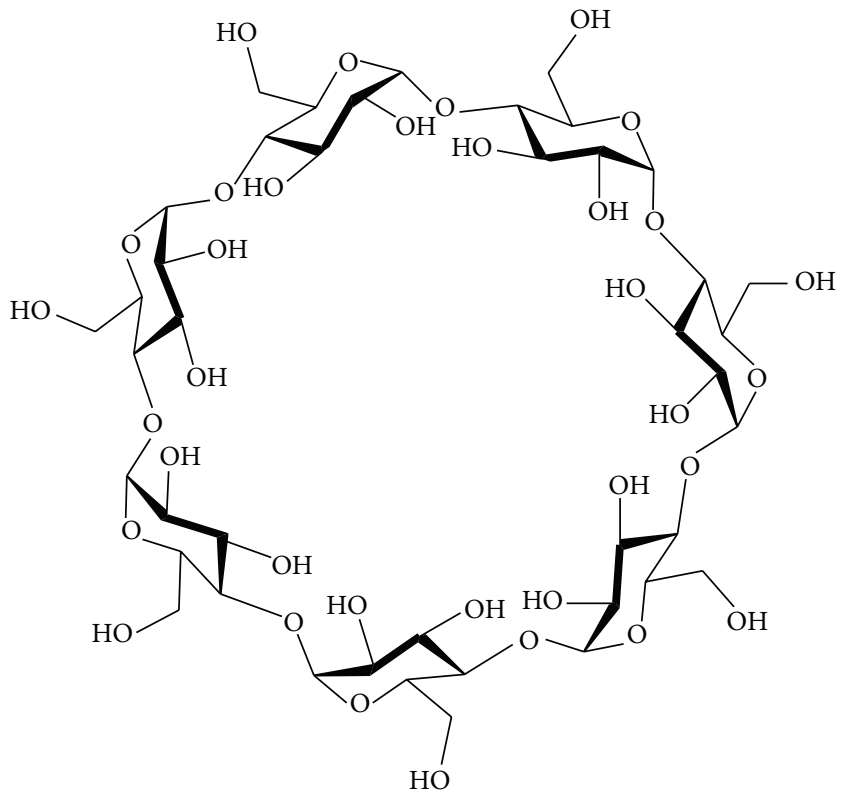

SCHEME 2: Chemical structure of $\beta$-CD.

[22]. They may affect the permeation properties of certain active ingredients and have been used to improve fragrance stability. CDs may be also used as emulsifiers in creams or lotions and in an underarm deodorant [22]. CDs have been shown to modify cutaneous absorption of active ingredients, although their overall benefit in this regard has yet to be proven [22]. Since they do not absorb UV or Vis light, CDs can protect a guest molecule from oxidation and photo degradation [6]. Therefore, microencapsulation of sunscreen agents has become recently an interested area of study [23].

Interaction between ethylhexyl-p-methoxycinnamate with unmodified and modified $\alpha$-, $\beta$-, and $\gamma$-CDs was studied by water phase solubility analysis. Although, photodegredation of sunscreen agent was significantly reduced by the formation of inclusion, comparative studies of the influence of $\mathrm{CDs}$ on stability showed that $\beta$-CD increases stability and limits adverse interactions of the UV filter with other formulation ingredients [24].

Recently, there hve been growing interests in utilizing molecular mechanics (MM) and modeling to study the inclusion complexes of CDs [25-27]. The MM calculation offers better understanding for the inclusion process by providing informative insights onto the energetically favored structure of the inclusion complexes, which is of particular importance in interpreting experimental results.

In the present study, the inclusion complexation of selected sunscreen filters, oxybenzone (Oxy), octocrylene (Oct), and ethylhexyl-methoxycinnamate (Cin) (Scheme 1) with $\beta$-CD (Scheme 2) in aqueous solution and solid phase was investigated by UV-Vis spectroscopy, differential scanning calorimetry (DSC), and,molecular mechanics (MM) calculations and modeling. The photostability of dermal preparations in the presence and absence of $\beta-C D$ was investigated by UV-vis spectrophotometry.

\section{Experimental}

2.1. Chemicals. $\beta$-Cyclodextrin $(\beta-C D)(\geq 97 \%$ purity) was supplied by Sigma-Aldrich Co. The sunscreen filters Oxy, Cin and Oct ( $98 \%$ purity) were kindly provided by ALFA Chemical Manufacture (Amman, Jordan), supplied from Haarmann and Reimer Germany (H\&R). Emulgade 1000 (cetostearyl alcohol), Eumulgin B1 (polyglycerol poly-12hydroxystearate), Lanette 16 (cetyl alcohol), Eutanol G (octyl dodecanol), Crodamol IPM (isopropyl myristate), glycerin, methyl paraben (MP), and propyl paraben (PP) were also kindly provided by ALFA Chemical Manufacture. Methanol, ethanol, and acetonitril of HPLC grade were purchased from Sigma-Aldrich. For photostability, formulation, in solid and liquid inclusion complexes, all solutions were freshly prepared with deionized water. All chemicals were used without further purification. Lotion with sun protection factor 30 (SPF 30) was provided by ALFA.

\subsection{Measurements and Methods}

2.2.1. Preparation of the Inclusion Complexes. All samples were prepared by dissolving about $200 \mathrm{mg}$ with different molar ratios $0: 1,1: 1$, and $2: 1$ of $[\beta-\mathrm{CD}]:$ [sunscreen agents]. Complexations with $\beta$-CD and sunscreen agents were done in methanol/water mixture $(85: 15, \mathrm{v} / \mathrm{v})$ with stirring in solution for 48 hours at room temperature. The solid form of the inclusion complexes was prepared by freeze-drying method. The solution was frozen by immersion in shell freezer and freeze-dried over $24 \mathrm{~h}$ in a Lyph lock 6 freeze dryer (Labconco). 
TABLE 1: Sunscreen lotion SPF 30 formula ingredients.

\begin{tabular}{lcc}
\hline Part & Ingredient name & Weight $(\mathrm{g})$ \\
\hline \multirow{3}{*}{ A } & Cin & 8 \\
& Oxy & 8 \\
& Oct & 6 \\
MP & 0.2 \\
& PP & 0.15 \\
\hline & Emulgade 1000 & 8 \\
B & Eumulgin B1 & 3 \\
& Lanette 16 & 3 \\
& Eutanol G & 3 \\
& IPM & 1 \\
\hline C & Glycerin & 5 \\
\hline D & HP- $\beta$-CD & $0-10$ \\
\hline
\end{tabular}

2.2.2. Inclusion in Formulation. Dry mixing method was used in preparation of inclusion paste. The inclusion paste was formed by mixing the three sunscreen agents Oxy, Cin, and Oct and preservatives methyl paraben (MB) and propyl paraben (PP) with different amounts of $\beta$-CD. The complexation took place by mixing the paste for more than 25 minutes. The thickness of the paste seems to depend almost on the amount of $\beta$-CD. Unfortunately, the guests (Oxy, Cin, Oct, MP, and PP) need a large amount of CDs to form equimolar ratio. Usually, in most formulations used in the pharmaceutical industry, cyclodextrins are added as additives in a few percent by weight. Accordingly, in this study the CD, were added in a few weight percent.

2.2.3. Sunscreen Lotion Formulation. The ingredients of the sunscreen lotion with sun protection factor (SPF) 30 are shown in Table 1. Procedure: Part A and C was mixed as described in the previous section. Part B was melted at $60^{\circ} \mathrm{C}$. Then, part (A and C) was mixed with part B and hot water $\left(60^{\circ} \mathrm{C}\right)$ was added to the mixture. Then, the mixture was cooled to room temperature. Note that a continuous stirring should be carried out through all steps. Lotion sample was prepared by dissolving about $150 \mathrm{mg}$ of lotion using a mixture of ethanol and water $(85: 15 \mathrm{v} / \mathrm{v})$, and then the solution was diluted to $500 \mathrm{~mL}$.

2.2.4. UV-Vis Spectrophotometry Measurements. UV-Vis spectra were recorded with a Shimadzu single beam UV-Vis spectrophotometer (UV-2401 (PC) S). The spectra of the sunscreen agent inclusion complexes were recorded in a mixture of alcohol (methanol or ethanol) and water in $1 \mathrm{~cm}$ cuvette; for inclusion experiments the concentration of sunscreen agent was $\sim 30 \mu \mathrm{M}$, and $\beta$-CD was added in different molar ratios (one- to fourfold). Stirring time was ranged from two hours up to four days.

2.2.5. Thermal Analysis. Differential scanning calorimetry (DSC) measurements were carried out using Shimadzu DSC50 system equipped with a computerized data station TA- 5
WS/PC and with vented aluminum pans. Thermograms of $\sim 10 \mathrm{mg}$ samples were obtained by scanning within a temperature range of $50-400^{\circ} \mathrm{C}$ and scanning rate of $10^{\circ} \mathrm{C} / \mathrm{min}$. An empty pan was used as a reference.

2.2.6. ${ }^{13} \mathrm{C}$ NMR Study. The ${ }^{13} \mathrm{C}$ NMR spectra were recorded at $25^{\circ} \mathrm{C}$ using Bruker Model AC-200E spectrometer with $\mathrm{Me}_{4} \mathrm{Si}$ as an internal standard, operating at nominal ${ }^{13} \mathrm{C}$ frequencies $63 \mathrm{MHz}$. In all measurements the solvent was DMSO-d 6 .

2.2.7. MM Calculations. MM calculations were performed in vacuum using Hyperchem software (release 4, Hyperchem Inc., Waterloo, ON, Canada) and MM+ force field. A relative permittivity of 1.5 and conjugate gradient algorithm of $0.1 \mathrm{Kcal} / \mathrm{mol} \AA$ were applied for electrostatic interaction and minimization, respectively. The $\beta-\mathrm{CD}$ structure was built using previously published X-ray diffraction data [28]. Geometrical energies for $\beta$-CD and drugs' structures were minimized using the $\mathrm{MM}+$ force field. The inclusion process was simulated by positioning the $\mathrm{O} 4$ glucosides atoms at the Cartesian coordinates' origin; the $\beta-\mathrm{CD}$ was held fixed at the original while allowing the guest molecule to approach and penetrate inside the $\beta$-CD cavity. Simulations were performed while the guest molecule approaches toward the wide and narrow rim, alternatively. Since each molecule may approach the $\beta-C D$ cavity through different parts of the molecule, MM calculations were performed based on the inclusion of different parts of each guest molecule.

2.2.8. Photostability Study. The photolysis experiments were performed by using a 150-Watt Mercury UV immersion lamp (Heraus). Photostability of all sunscreen agents was studied separately and as a mixture in lotion. The photolysis cell temperature was controlled by a flow of tap water through the photolysis jacket. The temperature was always less than $40^{\circ} \mathrm{C}$. At this temperature there is no thermal degradation expected for the three sunscreen agents. The photostability of sunscreen lotion has been studied in the absence and presence of $\beta$-CD. The sunscreen lotions were prepared according to the common procedure described previously in this section. The photostability experiments were performed in cream formulations (oil-in-water emulsion) containing sunscreen lotions $(2 \%, \mathrm{w} / \mathrm{w})$ alone or complexed with $\beta$-CD. The concentration of sunscreen lotions was held constant for all the cream formulations. One hundred microliters of the lotions or cream formulations was spread, as uniform as possible by circular movements of a gloved finger, onto a $50 \mathrm{~cm}^{2}$ glass plate $\left(2 \mathrm{mg} / \mathrm{cm}^{2}\right)$. Ten minutes after applications, the plate was exposed to UV radiation for $1 \mathrm{~h}$. For each UV radiation dose, another plate was kept in dark as a control. After exposure, the samples were ultrasonically dissolved in $10^{3} \mu \mathrm{L}$ of methanol for $2 \mathrm{~min}$. Then, the solution was transferred to a $10 \times 100 \mathrm{~mm}$ glass tube and dried under nitrogen at room temperature. The dried extract was reconstituted with $2 \mathrm{~mL}$ of methanol analyzed by UV-Vis spectrophotometer (diluted to $15 \mu \mathrm{L} / \mathrm{mL}$ ). The results were the average of five experiments. 


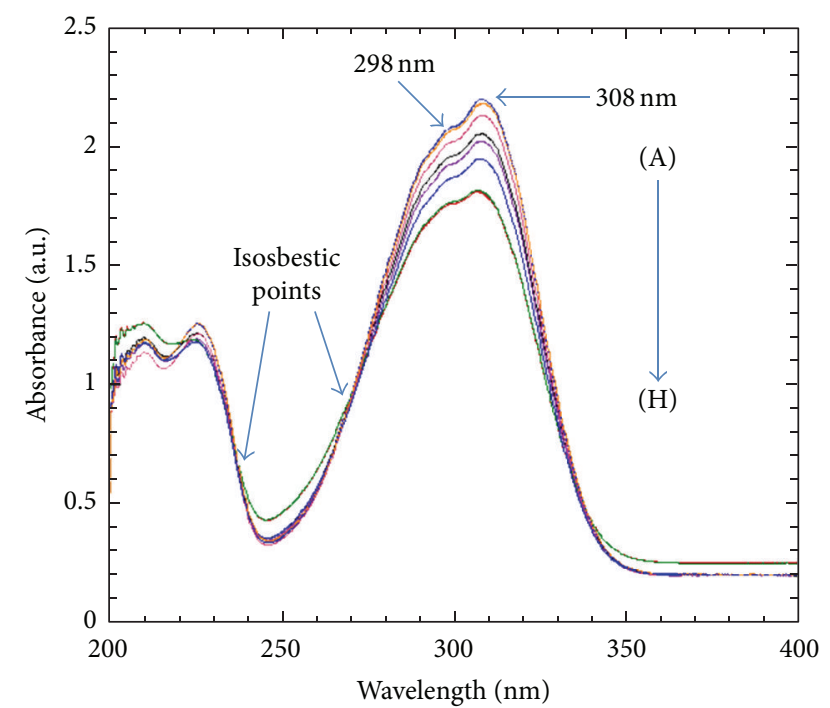

FIGURE 1: Absorption spectra of Cin $(3.70 \mathrm{mM})$ in methanol/water mixture $(85: 15, \mathrm{v} / \mathrm{v})$ as a function of $\beta$-CD's concentration at $25^{\circ} \mathrm{C}$. [ $\beta$-CD] (M): (A) 0; (B) 1.50; (C) 3.01; (D) 4.56; (E) 6.21; (F) 7.98; (G) 9.45; $(\mathrm{H})$ 11.00. Stirring time: 6 hours.

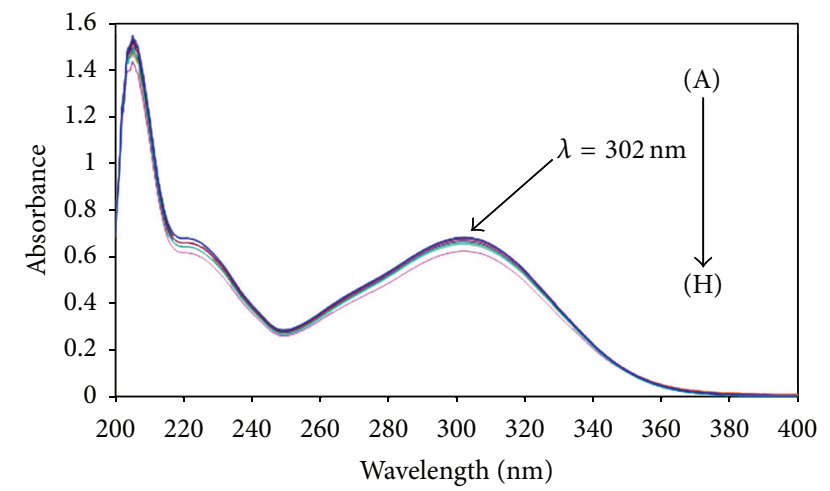

FIgURE 2: Absorption spectra of Oct $(2.77 \mathrm{mM})$ in methanol/water mixture $(85: 15, \mathrm{v} / \mathrm{v})$ as a function of $\beta$-CD's concentration at $25^{\circ} \mathrm{C}$. [ $\beta$-CD] (M): (A) 0; (B) 1.51; (C) 3.02; (D) 4.53; (E) 6.04; (F) 7.55; (G) 9.06; (H) 10.57. Stirring time: 6 hours.

The sunscreen assay was monitored by UV-Vis spectrophotometer. The UV-Vis spectra of the sample have been recorded before and after three hours of irradiation in time interval of one hour.

\section{Results and Discussion}

3.1. UV-Vis Spectrophotometry Study. Figures 1-3 show the UV-Vis spectra of Cin, Oct, and Oxy as a function of $\beta$ $\mathrm{CD}$ 's concentration at $25^{\circ} \mathrm{C}$, respectively. Inspecting of these spectra, one can observe that for Oxy, the absorption intensity is slightly changing in presence of $\beta$-CD, while larger changes can be observed for Oct. In contrast, the presence of $\beta$-CD at different concentrations has a noticeable effect on the absorption intensity of Cin. It is noteworthy to mention that assay determination for Cin was done by UV-Vis spectroscopy, and the absorption was taken at $\lambda_{\max }=308 \mathrm{~nm}$. It is well known

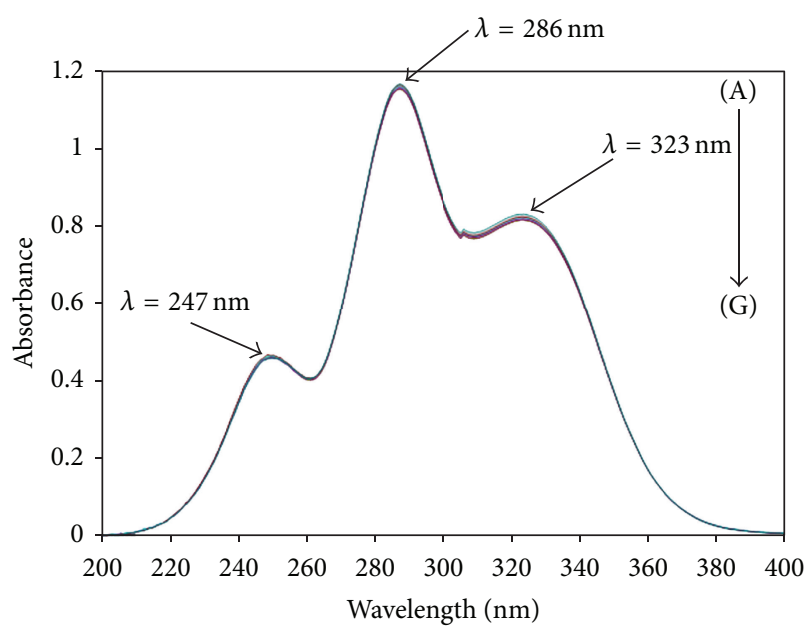

Figure 3: Absorption spectra of Oxy $(3.17 \mathrm{mM})$ in methanol/water mixture $(85: 15, \mathrm{v} / \mathrm{v})$ as a function of $\beta$-CD's concentration at $25^{\circ} \mathrm{C}$. [ $\beta$-CD] (M): (A) 0; (B) 1.56; (C) 3.13; (D) 4.69; (E) 6.25; (F) 7.81; (G) 9.37. Stirring time: 6 hours.

that the Cin has two isomers ( $\mathrm{E}$ and $\mathrm{Z}$ isomers). E-isomer has molar absorption coefficient $(\varepsilon)$ of $24000 \mathrm{M}^{-1} \mathrm{~cm}^{-1}$ at $\lambda_{\max }=$ $310 \mathrm{~nm}$ in methanol : water $(90: 10, \mathrm{v} / \mathrm{v})$, while $\varepsilon$ for Z-isomer at $\lambda_{\max }=310 \mathrm{~nm}$ is $12600 \mathrm{M}^{-1} \mathrm{~cm}^{-1}$ in the same solvent. The photoisomerization in solution is always in equilibrium $[29,30]$. The purchased raw material is assumed to have $100 \%$ of E-isomer, and the isomerization is known to be observed by exposing the sample to irradiation especially in dilute solutions at low concentration. Thus, the photoisomerization is expected to occur through the long time of stirring (three days).

Figure 1 shows the UV-Vis absorption spectra of the sunscreen filter (Cin) in absence and presences of different $\beta$-CD's concentration at room temperature $\left(25^{\circ} \mathrm{C}\right)$. Short looking at Figure 1 lets one conclude that the absorption intensity decreases with the concentration of $\beta$-CD and two isosbestic points were observed. The observation of two isosbestic points in the UV-Vis absorption spectra proposed the presence of two equilibria. These equilibria are attributed to two possibilities: the first is between Cin and $\beta$-CD in $1: 1$ and $1: 2$ molar ratio (Cin: $\beta$-CD), and the second is between two configurations of $\mathrm{Cin}$ ( $\mathrm{E}$ and $\mathrm{Z}$ isomers), whereas the two configurations of Cin have different values of extinction coefficient $(\varepsilon)$. Figure 4 shows the two Cin configurations.

Oct and Oxy have given small changes in absorption upon the inclusion by $\beta$-CD in methanol/water mixture (Figures 2 and 3). It is well known that through inclusion of the molecule within a CD cavity, its UV-Vis spectrum usually changes, due to partially or totally replacement of the salvation shell of the molecule by the $\mathrm{CD}$ molecule, which leads to new solute environment interactions [3]. In most studied cases, when the $\mathrm{CD}$ is added to an aqueous solution of an organic or inorganic substance significant changes in the position and intensity of the absorption spectra are observed. Thus, the small changes in absorption upon the inclusion of Oxy and Oct by $\beta$-CD suggest that the new solute environment interactions by $\beta$ $\mathrm{CD}$ are not significantly effective in case of Oxy and Oct. 


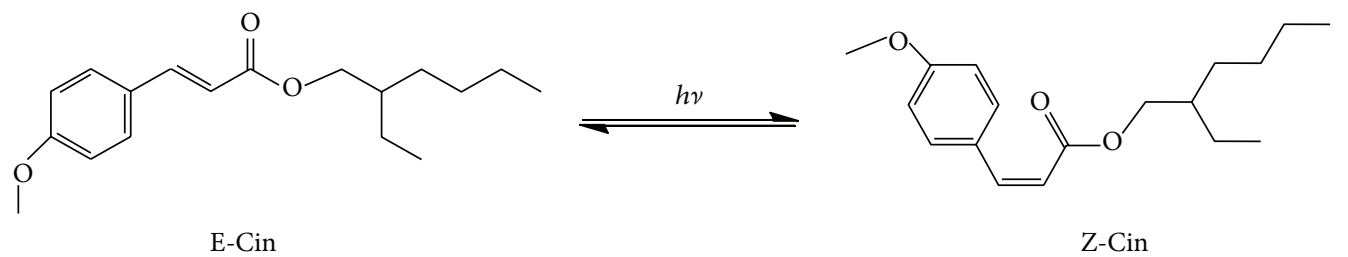

Figure 4: Chemical structure of E- and Z-Cin configuration.

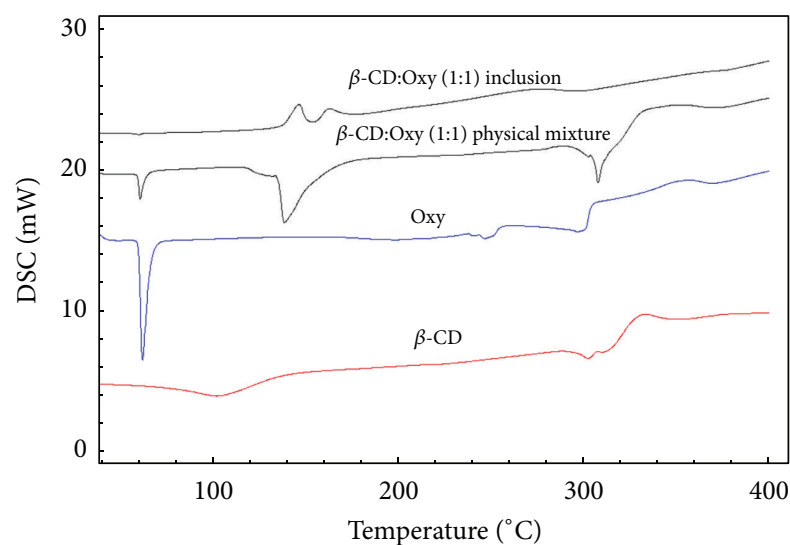

Figure 5: DSC thermograms of a $\beta$-CD : Oxy system. From top: Oxy $: \beta-C D$ inclusion complex, physical mixture of Oxy and $\beta-C D$, pure Oxy, and pure $\beta$-CD.

3.2. Thermal Analysis. Thermal analysis methods, particularly DSC, are widely used in pharmaceutical fields, ranging from control of raw materials to stability, and preformulation studies for development of new formulation [31]. In this study DSC is utilized to evident the complexation between sunscreen agents and CD. Typically, a shift or disappearance of the endothermic peak that corresponds to the melting or sublimation points of pure guest molecule is observed upon performing similar DSC analysis of the inclusion complex [32]. Figures 5-7 show the DSC thermograms of solid complexes (1:1 molar ratio), physical mixture (1:1 molar ratio), pure sunscreen agents (Oxy, Cin, and Oct), and pure $\beta-C D$.

As can be noticed from Figures 5-7, the DSC thermogram of $\beta$-CD has two peaks: one broad endothermic peak above $100^{\circ} \mathrm{C}$, corresponding to the release of water from $\beta$-CD [33], and another less broad endothermic peak above $300^{\circ} \mathrm{C}$, corresponding to the decomposition of $\beta$-CD. Furthermore, the DSC thermogram of Oxy (Figure 5) exhibits a sharp endothermic peak at approximately $65^{\circ} \mathrm{C}$, corresponding to the melting of Oxy, that hardly appeared in the physical mixture of Oxy and $\beta$-CD and completely disappeared for the inclusion complex (Figure 5). This observation confirms the formation of the inclusion complex of Oxy with $\beta$ CD. Figure 6 shows the thermograms for the Cin sunscreen agent; as can be observed from this figure, the thermogram of the physical mixture of $\mathrm{Cin}: \beta-\mathrm{CD}$ was different from that of inclusion complex of $\mathrm{Cin}: \beta$-CD (Figure 6); this observation confirms the formation of the inclusion complex of Cin with $\beta$-CD. Figure 7 shows the thermograms for the

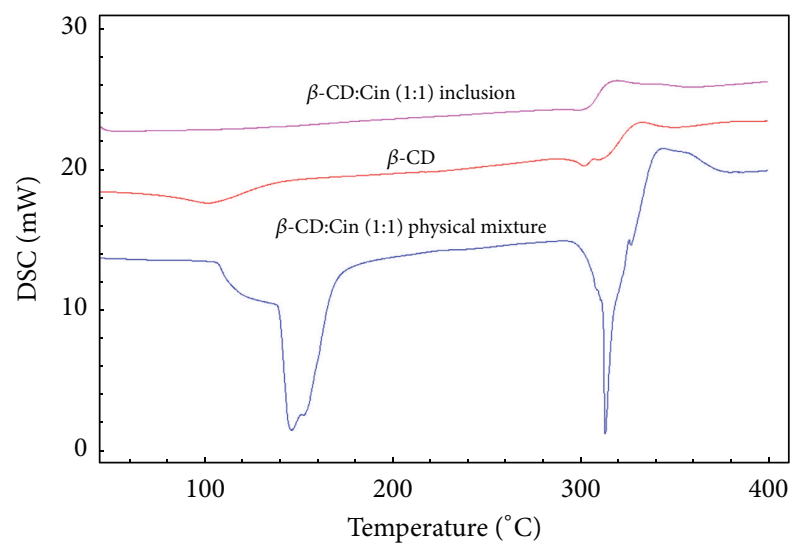

FIgURE 6: DSC thermograms of a $\beta$-CD : Cin system. From top: Cin : $\beta$-CD inclusion complex, pure $\beta-C D$, and physical mixture of Cin and pure $\beta$-CD.

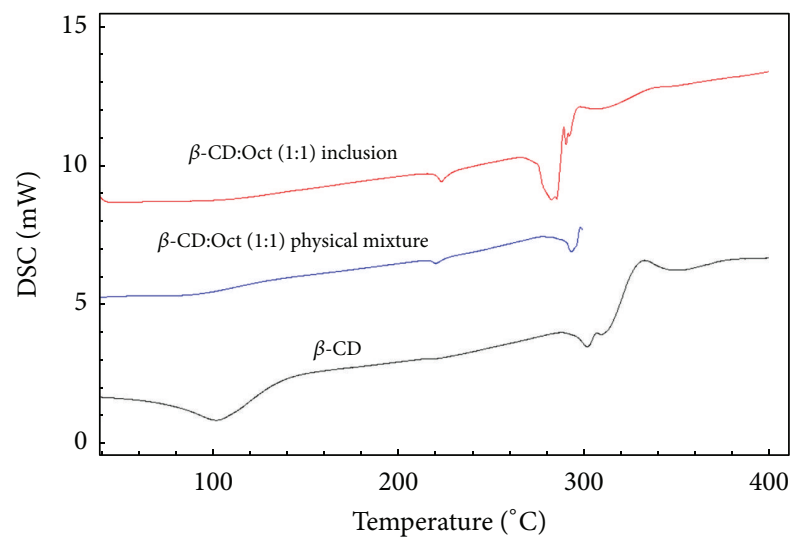

FIgURE 7: DSC thermograms of a $\beta$-CD : Oct system. From top: Oct : $\beta$-CD inclusion complex, pure $\beta-\mathrm{CD}$, and physical mixture of Oct and pure $\beta$-CD.
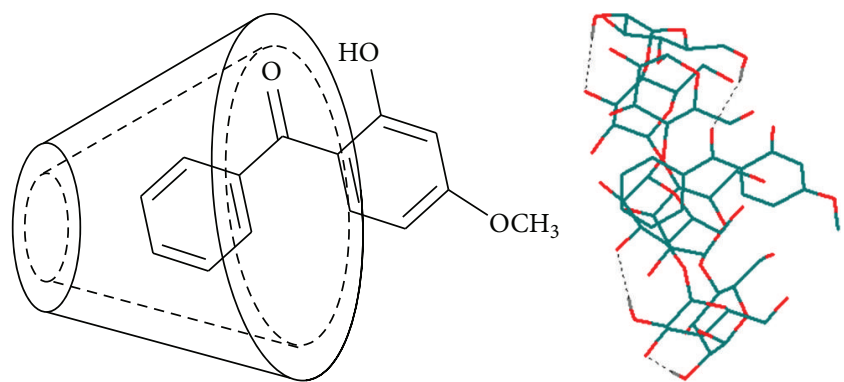

FIgURE 8: Hypothetical structure of Oxy : $\beta$-CD inclusion complex. 

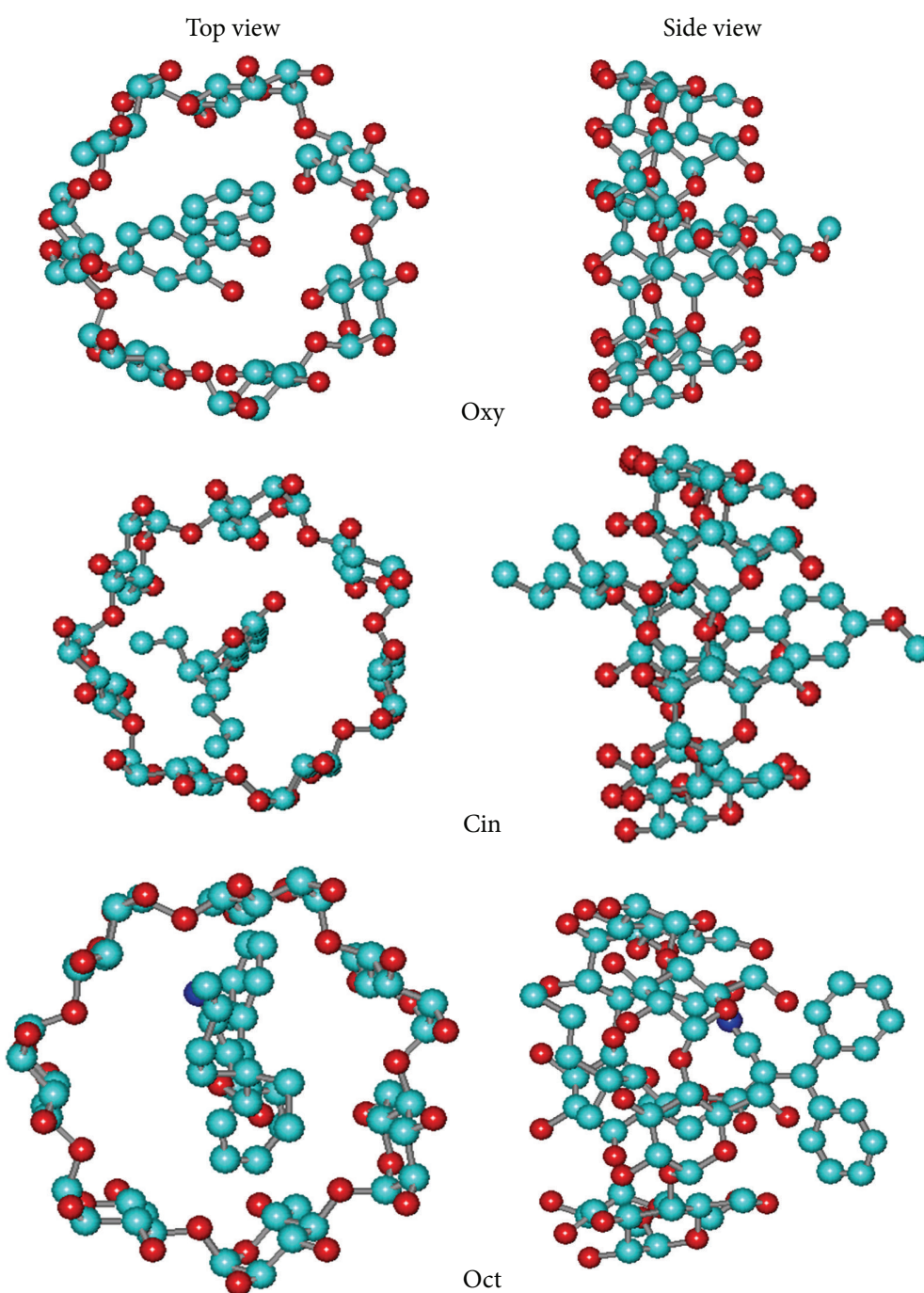

FIgURE 9: Side and top views for the proposed models of the energetically favored configurations of sunscreen agents: $\beta$-CD inclusion complexes.

Oct sunscreen agent; as can be observed from this figure, the thermogram of the physical mixture of Oct: $\beta$-CD was similar to that of inclusion complex of Oct: $\beta$-CD (Figure 7); this indicated that inclusion of Oct with $\beta$-CD could properly take place in both types of preparations, by physical mixing and by solution mixing followed by removal of solvent. These sunscreen agents are known to be affected by both mixing time and delay time before doing the thermal analysis. Since both $\mathrm{Cin}$ and Oct sunscreen agents are liquid below room temperature $\left(25^{\circ} \mathrm{C}\right)$, the DSC thermograms of pure Cin and Oct could not be measured.

3.3. ${ }^{13}$ C NMR Study. Here, we have addressed the possible complexation/inclusion of the three sunscreens (Oxy, Cin, and Oct) in $\beta$-CD with ${ }^{13} \mathrm{C}$ NMR spectroscopy, combined with other complementary characterization techniques (such as DSC). The ${ }^{13} \mathrm{C}$ NMR spectra for the pure sample of sunscreen agents (Oxy, Cin, and Oct) were compared to the spectra of their complexes with $\beta$-CD in order to identify the shifts that could provide evidence for complexation phenomena. The results of this study were summarized in Table 2.

Table 2 shows the ${ }^{13} \mathrm{C}$ chemical shifts of the free sunscreen agents and in the presence of complex-forming agent $(\beta-C D)$, as well as the shift differences between equivalent spectral points of the free sunscreen agents and their inclusion complexes with $\beta$-CD. From these results it can be seen that both positive and negative shielding effects occur, in which the magnitude of the shielding changes was larger for the carbon atoms of the phenyl groups of the sunscreen agents. These shifts may be result of either a higher shielding of carbon atoms of phenyl group in the $\beta$-CD cavity or a larger stability in the equilibrium between complexes and free sunscreen agents (or both) [34]. It is hard to determine the exact structure of the complexes based on NMR data, specially the orientation of $\beta$-CD rims. However, Figure 8 shows a typical 1:1 inclusion complex structure for Oxy with $\beta$-CD based on ${ }^{13} \mathrm{C}$ NMR shifts. 
TABLE $2:{ }^{13} \mathrm{C}$ chemical shifts of pure sunscreen agents (Oxy, Cin, and Oct), their inclusion complex with $\beta$-CD, and the differences between the free sunscreens and the inclusion complexes.

\begin{tabular}{lccccccccccc}
\hline $\begin{array}{l}\text { Oxy } \\
\text { atom }\end{array}$ & $\begin{array}{c}\text { Oxy } \\
(\mathrm{ppm})\end{array}$ & $\begin{array}{c}\text { Oxy: } \beta-\mathrm{CD} \\
(\mathrm{ppm})\end{array}$ & $\begin{array}{c}\Delta \delta \\
(\mathrm{ppm})\end{array}$ & $\begin{array}{c}\text { Cin } \\
\text { atom }\end{array}$ & $\begin{array}{c}\mathrm{Cin} \\
(\mathrm{ppm})\end{array}$ & $\begin{array}{c}\text { Cin: } \beta-\mathrm{CD} \\
(\mathrm{ppm})\end{array}$ & $\begin{array}{c}\Delta \delta \\
(\mathrm{ppm})\end{array}$ & $\begin{array}{c}\text { Oct } \\
(\mathrm{ppm})\end{array}$ & $\begin{array}{c}\text { Oct: } \beta \text {-CD } \\
(\mathrm{ppm})\end{array}$ & $\begin{array}{c}\Delta \delta \\
(\mathrm{ppm})\end{array}$ \\
\hline 1 & 199.1 & 199.1 & 0.0 & 9 & 166.3 & 166.9 & 0.6 & 12 & 168.5 & 169.0 & 0.5 \\
9 & 165.6 & 165.7 & 0.1 & 16 & 161.2 & 161.4 & 0.2 & 9 & 162.5 & 162.0 & -0.5 \\
7 & 164.3 & 164.3 & 0.0 & 11 & 143.8 & 144.5 & 0.7 & 14 & 139.0 & 138.5 & -0.5 \\
2 & 138.4 & 138.1 & -0.3 & 12 & 129.5 & 130.4 & 0.9 & 13 & 139.0 & 139.2 & 0.2 \\
11 & 134.9 & 134.0 & -0.9 & 13 & 129.6 & 126.8 & -2.8 & 11 & 116.8 & 116.5 & -0.3 \\
5 & 132.2 & 132.3 & 0.1 & 14 & 129.6 & 129.2 & -0.4 & 10 & 104.6 & 104.6 \\
3 & 128.0 & 129.1 & 1.1 & 10 & 115.1 & 114.7 & -0.4 & 8 & 168.5 & 169.0 \\
4 & 128.4 & 128.9 & 0.5 & 15 & 114.1 & 112.1 & -2.0 & 15 & 128.3 & 129.5 \\
6 & 114.0 & 114.3 & 0.3 & 8 & 62.2 & 63.0 & 0.8 & 17 & 128.3 & 129.5 \\
10 & 107.3 & 107.4 & 0.1 & 17 & 54.8 & 55.1 & 0.3 & 16 & 128.6 & 130.0 \\
8 & 101.5 & 101.6 & 0.1 & & & & & 19 & 128.6 & 130.0 \\
12 & 55.9 & 56.1 & 0.2 & & & & & & 1.4 & 1.4 \\
\hline
\end{tabular}

3.4. MM Calculations. All calculations were performed using the Hyperchem software package. Importantly, the focal benefit of performing MM calculations is to provide some insights on the inclusion process that can support the experimental findings. In order to provide comprehensive computational analysis, two principal modes were considered: inclusion through the wide and narrow rims of $\beta$-CD cavity. In addition, various parts of the proposed sunscreen agents' molecules were allowed to penetrate inside the $\beta$ $\mathrm{CD}$ cavity. Scheme 3 shows the reference atoms of Oxy, Cin, and Oct. Thus, each sunscreen agents' molecule would form inclusion complex with $\beta$-CD via a variety of configurations; for example, Oxy and Cin have two sides of approaching $\beta-\mathrm{CD}$ cavity via which it can form the inclusion complex. Therefore, a total of four possible configurations are expected for Oxy- $\beta-C D$ and Cin- $\beta-C D$ complexes. While Oct has three reference points of approaching, a total of six possible configurations are expected for Oct- $\beta$-CD.

The energy changes $(\Delta E)$ or energy of binding $\left(E_{\text {binding }}\right)$ accompanying the formation of $1: 1$ inclusion complex between the proposed sunscreen agents' molecule and $\beta$-CD was considered for judging the most stable configurations of the complex. The $\Delta E$ was estimated based on the following equation:

$$
\Delta E_{\text {binding }}=E_{(\text {complex })}-\left[E_{\text {(guest) }}+E_{(\beta-\mathrm{CD})}\right] \text {, }
$$

where $E_{\text {(complex) }}, E_{\text {(guest) }}$, and $E_{(\beta-\mathrm{CD})}$ are the total energies of the complex, the isolated guest and the isolated host $(\beta-C D)$, respectively. A negative value for $\Delta E_{\text {binding }}$ indicates that a stable inclusion complex can be formed between guest and $\beta$ $\mathrm{CD}$. Also, the calculations were performed in vacuum phase without considering the solvation effect.

It is worth mentioning that the inclusion complexation process is driven via a combination of forces; this includes electrostatic, van der Waals, bond angle bending, and dihedral angle bending forces. The predominant contribution to the $E_{\text {binding }}$ comes from the van der Waals forces, whereas the

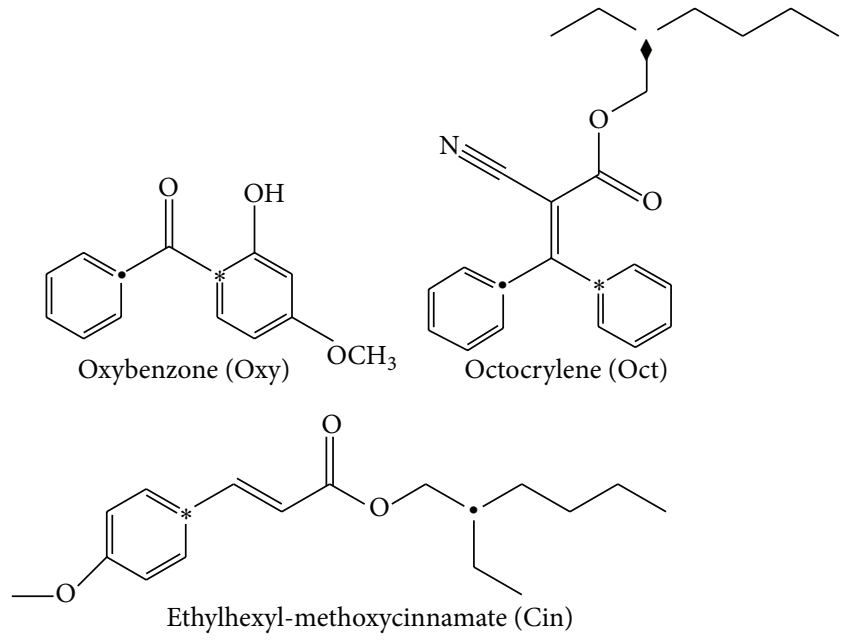

Scheme 3: Reference carbon atoms used in molecular modeling approach.

electrostatic contribution is very small. Contribution from other forces was neglected.

Table 3 summarizes the values for the $E_{\text {binding, }}$, $E_{\text {vanderWaals }}$, and $E_{\text {static }}$ for all possible configurations of the inclusion complexes of the proposed sunscreen agents with $\beta$-CD. The $E_{\text {binding }}$ for the approach of each part in the sunscreen agents' molecule with $\beta-\mathrm{CD}$ was computed and summarized. The optimal $E_{\text {binding }}$ was determined as the minima of the plot of $E_{\text {binding }}$ versus the $x$-coordinate. Accordingly, the favorable configuration for the inclusion complex of each sunscreen agents' molecule with $\beta-C D$ is shown in Figure 9 with side and top views. The calculations were carried out for the three sunscreen agents based on their tendency to form 1:1 inclusion complexes.

The MM results show that the three sunscreen agents can be included in $\beta$-CD cavity, in the following preference: Oct $>$ Cin $>$ Oxy. This arrangement is anticipated from the 
TABLE 3: Binding, van der Waals, and electrostatic energies with selected components at the minimum binding energy (global) for Oxy, Cin, and Oct through two rims of $\beta$-CD.

\begin{tabular}{|c|c|c|c|c|}
\hline Approach type & Global minimum position & $\begin{array}{c}E_{\text {(Binding Energy) }} \\
\text { Kcal/mol }\end{array}$ & $\begin{array}{c}E_{\text {(van der Waals) }} \\
\text { Kcal/mol }\end{array}$ & $\begin{array}{c}E_{\text {(Electrostatic) }} \\
\text { Kcal/mol } \\
\end{array}$ \\
\hline Oxy phenyl $(\mathrm{C} *)$ wide rim & 0 & -19.5725 & -19.4914 & -0.0812 \\
\hline Oxy phenyl $(C *)$ narrow rim & 1 & -16.0894 & -16.1879 & 0.0984 \\
\hline Oxy phenyl $(\mathrm{C} \bullet)$ wide rim & 2 & -17.0286 & -16.712106 & -0.3164 \\
\hline Oxy phenyl $(\mathrm{C} \bullet$ ) narrow rim & 1 & -15.6841 & -16.1880 & 0.5040 \\
\hline Cin phenyl $(\mathrm{C} *)$ wide rim & 3 & -13.9190 & -13.6366 & -0.2826 \\
\hline Cin phenyl $(\mathrm{C} *)$ narrow rim & 1 & -20.4268 & -20.5780 & 0.1512 \\
\hline Cin hexyl (C•) wide rim & 1 & -23.9382 & -23.5574 & -0.3808 \\
\hline Cin hexyl $(\mathrm{C} \bullet)$ narrow rim & 1 & -22.0728 & -22.4545 & 0.3818 \\
\hline Oct phenyl $(\mathrm{C} *)$ wide rim & 6 & -22.5716 & -23.0228 & 0.4511 \\
\hline Oct phenyl $(\mathrm{C} *)$ narrow rim & 5 & -29.1671 & -28.4832 & -0.6838 \\
\hline Oct phenyl $(\mathrm{C} \bullet)$ wide rim & 6 & -23.0966 & -23.4717 & 0.3751 \\
\hline Oct phenyl $(\mathrm{C} \bullet)$ narrow rim & 5 & -25.2024 & -24.6128 & -0.5896 \\
\hline Oct hexyl (C ) wide rim & 2 & -27.3691 & -26.9794 & -0.3898 \\
\hline Oct hexyl (C narrow rim & 3 & -26.8211 & -27.2557 & 0.4345 \\
\hline
\end{tabular}

binding energy $\left(E_{\text {binding }}\right)$ for each. This result was noticed for Oct; that it form inclusion within a few minutes when it is monitoring by UV-spectroscopy scanning. Each guest may have a favored approach; Oct has three approaches, the best one isfrom trans phenyl to nitrile and the second from alkyl part then from phenyl cis with nitrile. Steric effect and hydrogen bond formation are the main factor in this case. Usually wide CD rim approach is preferred. This does not happen in Oct approaches from both phenyls, because Oct's geometry cannot accommodate well in $\beta$-CD.

The complexation in water shows that the van der Waals interactions are the predominant contribution to the stabilization of the complexes formed, in which the water molecules forms a cage around the complex and no water molecule penetrates inside the $\beta$-CD hydrophobic cavity.

3.5. Inclusion in Formulation and Photostability Study. The main goal of complexation of sunscreens agents with cyclodextrins is to enhance the stability, photostability, and wettability of sunscreens agents and to reduce its skin penetration. Loftsson and Masson showed that the effect on skin penetration may be related to cyclodextrin concentration, with reduced flux generally observed at relatively high cyclodextrin concentrations [35]. At higher cycoldextrin concentrations, the excess cyclodextrin would be expected to complex free sunscreens agents and hence reduce skin penetration.

In this study, sunscreen lotion formulation has been prepared aiming to enhance the performance of the sunscreen products. It has been noticed that the prepared lotion containing $\beta$-CD has gained an excellent physical compatibility. The first observation is that it looked similar to the lotion without $\beta-\mathrm{CD}$, and it was difficult to distinguish between them. By increasing the amount of $\beta$-CD, it becomes thicker. On the other hand, the other physical properties were indistinguishable such as, spreadability, color, and application.

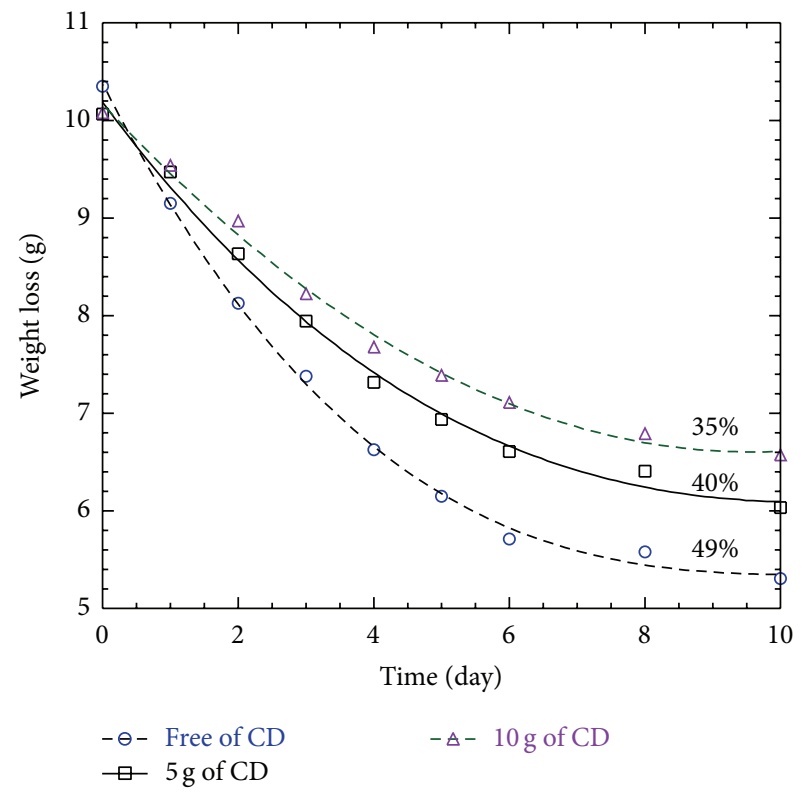

FIGURE 10: Loss in mass of sunscreen lotion along ten days with different amounts of $\beta$-CD: Free of $\beta$-CD, $5 \mathrm{~g}$ of $\beta-\mathrm{CD}$, and $10 \mathrm{~g}$ of $\beta$-CD.

Figure 10 shows the resistance of lotion containing $\beta$-CD to dehydration. It was observed that loss in lotion's weight was decreased as the amount of $\beta$-CD increased. The percentage losses due to dehydration after ten days at room temperature were $49 \%, 40 \%$, and $35 \%$ with the addition of 0,5 , and $10 \mathrm{~g}$ of $\beta$-CD, respectively. The result of this study suggested that $10 \mathrm{~g}$ of $\beta$-CD shifted the equilibrium of the complexation reaction towards the complexed form (less dehydration percentage), thereby reducing the amount of free sunscreen agent available for permeation and slowing the rate of skin permeation. Therefore, the higher concentrations of $\beta$-CD may create 


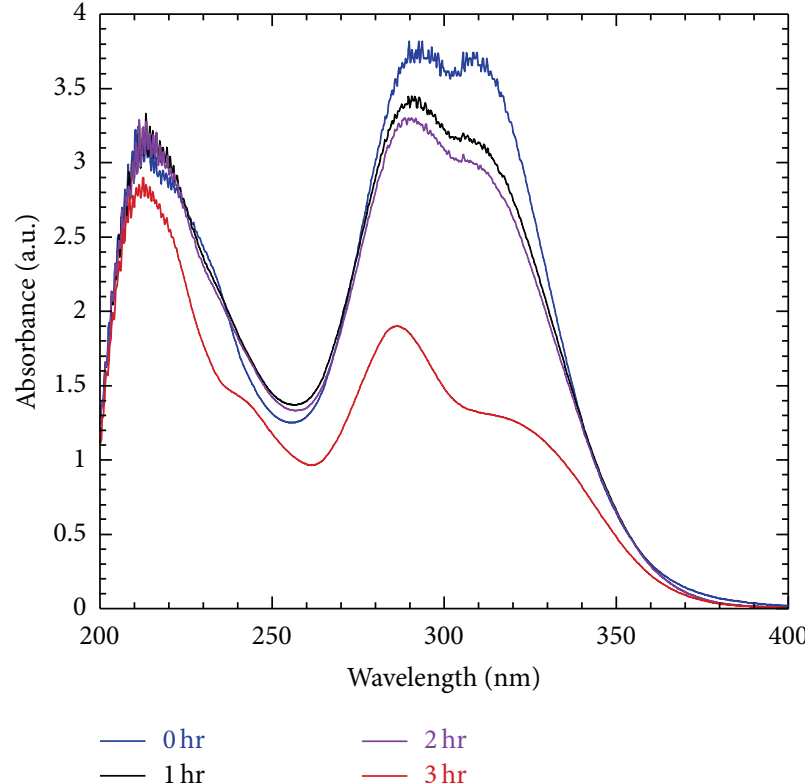

(a)

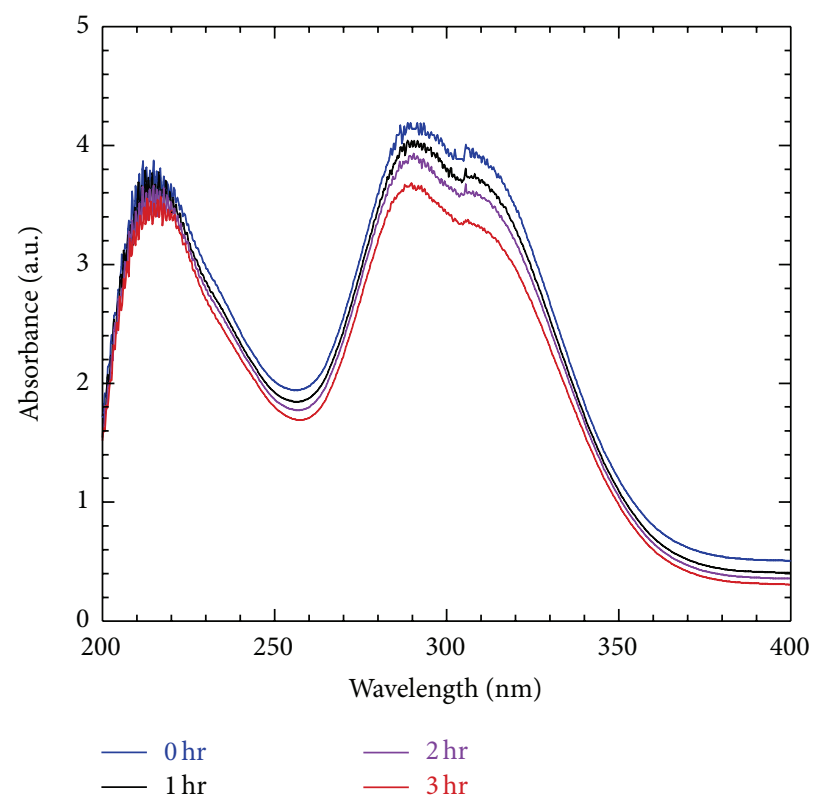

(b)

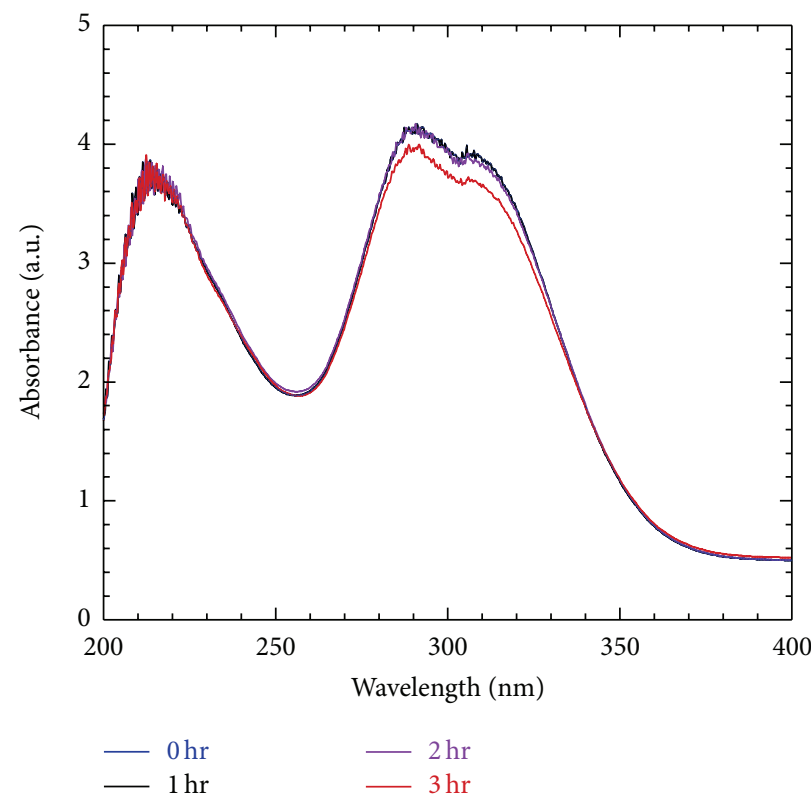

(c)

FIGURE 11: Change in absorption spectra of cream sample after different times of irradiation in the absence and presence of $\beta$-CD. Irradiation time: $0,1,2$, and 3 hours. (a) Free of $\beta$-CD; (b) $5 \mathrm{~g} \beta$-CD; (c) $10 \mathrm{~g} \beta$-CD.

a drug reservoir on the skin surface. This is of great importance for the performance of sunscreen products since the UV-absorbing agents must remain in the outermost layer of the skin to be effective. The percentage losses due to dehydration and because the amount of $\beta-\mathrm{CD}$ shifted the equilibrium of the complexation reaction towards the complexed form were similar to that observed for using hydroxypropyl- $\beta$-CD in our earlier study [21].

The influence of $\beta$-CD on the photodegradation process of cream formulations was investigated by UV-Vis spectrophotometric (Figure 11); hence, inclusion complexation with $\beta$-CD has significantly retarded the rate of the photodegradation reaction of cream formulations. The spectrum obtained from the cream formulations-methanol solution free of $\beta$-CD exhibited an absorption maxima at 287 and $309 \mathrm{~nm}$ (Figure 11(a)). These characteristic absorption maxima of sunscreen agents were also observed from the cream formulations with 5 and $10 \mathrm{~g}$ of $\beta$-CD solutions sample at 285 and $307 \mathrm{~nm}$ (Figures 11(b) and 11(c)). The slightly blue shift could be attributed to the formation of inclusion complexes in the sample and the more hydrophilic environment surrounding sunscreen agents. Furthermore, it is clear that, after 
the addition of 5 and $10 \mathrm{~g}$ of $\beta$-CD (Figures 11(b) and 11(c)) the photostability of cream formulations was significantly increased compared to that in absence of $\beta-\mathrm{CD}$ (Figure 11(a)). The spectra shown in Figure 11 indicate that there is a synergetic effect between $\beta-\mathrm{CD}$ and other lotion ingredients.

Typically, the enhancement of the photostability of the molecules in the presences of cyclodextrins can be attributed to the inclusion of the guest molecule inside the CD's cavity, either partially or entirely. Hence the photostabilization effect of the examined cyclodextin $(\beta-\mathrm{CD})$ correlated with their complexation strength with the tested sunscreen agents.

We believe that the results of this study demonstrate that $\beta$-CD can be utilized as a photostabilizer additive for enhancing the photostability of sunscreen agent's molecules. Moreover $\beta$-CD can act as a reservoir for the sunscreen agents on the skin surface which will reduce its transdermal permeation.

\section{Conclusion}

In the present study, we have demonstrated the ability of $\beta$-CD to form inclusion complexes with selected sunscreen agents, namely, Oxy, Cin, and Oct. The formation of the inclusion complexes was confirmed experimentally using DSC, ${ }^{13} \mathrm{C}$ NMR, and theoretically MM calculations and modeling. The NMR data agree well with MM results; thus modeling has been used to describe details of the structural, energetic, and dynamic features of host-guest complex.

MM calculations revealed that Oxy exhibited slight preference for inclusion through the wide rim over the narrow rim of the $\beta$-CD, whereas Cin and Oct exhibited significant preference to penetrate through the narrow rim, which could be mainly attributed to the large geometrical sizes of the Cin and Oct molecules.

The results of spectrophotometric study has shown that the inclusion complexation with $\beta$-CD has the potential to enhance the photostability of the selected sunscreen agents in lotion. Retarding the photodecomposition of the sunscreen agents' molecule in the presences of $\beta$-CD can be attributed mainly to the protection role of $\beta$-CD upon including the sunscreen agents' molecule inside its cavity. The results were highly consistent with Oxy and Cin photostability studies. The present study provides an insight on the importance of investigating the photostability of sunscreen agents' molecules and proposes a remedy for enhancing such imperative property.

\section{Conflict of Interests}

The authors do not have a direct financial relation with the ALFA Chemical Manufacture, Amman, Jordan (commercial identity mentioned in experiment section) that might lead to a conflict of interests for any of the authors.

\section{Acknowledgments}

Financial support by Deanship of Research at Jordan University of Science and Technology (Grant no. 30/2003) is deeply appreciated.

\section{References}

[1] M. L. Bender and M. Komiyama, Cyclodextrin Chemistry, Springer, Berlin, Germany, 1978.

[2] H. Dodziuk, Cyclodextrins and Their Complexes: Chemistry, Analytical Methods, Applications, Wiley-VCH, Weinheim, Germany, 2006.

[3] J. Szejtli, "Introduction and general overview of cyclodextrin chemistry," Chemical Reviews, vol. 98, no. 5, pp. 1743-1753, 1998.

[4] D. Duchêne, Cyclodextrins and Their Industrial Uses, De Santé, Paris, France, 1987.

[5] S. Z. Lin, D. Wouessidjewe, M. C. Poelman, and D. Duchêne, "Indomethacin and cyclodextrin complexes," International Journal of Pharmaceutics, vol. 69, no. 3, pp. 211-219, 1991.

[6] A. D. Bani-Yaseen, N. F. Al-Rawashdeh, and I. Al-Momani, "Influence of inclusion complexation with $\beta$-cyclodextrin on the photostability of selected imidazoline-derived drugs," Journal of Inclusion Phenomena and Macrocyclic Chemistry, vol. 63, no. 1-2, pp. 109-115, 2009.

[7] A. A. Dawoud and N. Al-Rawashdeh, "Spectrofluorometric, thermal, and molecular mechanics studies of the inclusion complexation of selected imidazoline-derived drugs with $\beta$ cyclodextrin in aqueous media," Journal of Inclusion Phenomena and Macrocyclic Chemistry, vol. 60, no. 3-4, pp. 293-301, 2008.

[8] N. A. F. Al-Rawashdeh, "Interactions of nabumetone with $\gamma$ cyclodextrin studied by fluorescence measurements," Journal of Inclusion Phenomena and Macrocyclic Chemistry, vol. 51, no. 1, pp. 27-32, 2005.

[9] N. A. F. Al-Rawashdeh, I. A. Abu-Yousef, and S. M. Kanan, "Cyclic voltammetry study of asymmetrical trityl di- and trisulfides on coated and bare gold electrodes," Journal of Physical Chemistry C, vol. 112, no. 17, pp. 7062-7068, 2008.

[10] N. A. F. Al-Rawashdeh, A. M. Al-Ajlouni, S. B. Bukallah, and N. Bataineh, "Activation of $\mathrm{H}_{2} \mathrm{O}_{2}$ by methyltrioxorhenium(VII) inside b-cyclodextrin," Journal of Inclusion Phenomena and Macrocyclic Chemistry, vol. 70, no. 3-4, pp. 471-480, 2011.

[11] G. Cravotto, A. Binello, E. Baranelli, P. Carraro, and F. Trotta, "Cyclodextrins as food additives and in food processing," Current Nutrition and Food Science, vol. 2, no. 4, pp. 343-350, 2006.

[12] T. Loftsson and D. Duchêne, "Cyclodextrins and their pharmaceutical applications," International Journal of Pharmaceutics, vol. 329, pp. 1-11, 2007.

[13] D. L. Kirschner, M. Jaramillo, and T. K. Green, "Enantioseparation and stacking of cyanobenz[f]isoindole-amino acids by reverse polarity capillary electrophoresis and sulfated $\beta$ cyclodextrin," Analytical Chemistry, vol. 79, no. 2, pp. 736-743, 2007.

[14] G. S. Yang, D. M. Chen, Y. Yang et al., "Enantioseparation of some clinically used drugs by capillary electrophoresis using sulfated $\beta$-cyclodextrin as a chiral selector," Chromatographia, vol. 62 , no. 7-8, pp. 441-445, 2005.

[15] W. H. Henley, R. T. Wilburn, A. M. Crouch, and J. W. Jorgenson, "Flow counterbalanced capillary electrophoresis using packed capillary columns: resolution of enantiomers and isotopomers," Analytical Chemistry, vol. 77, no. 21, pp. 7024-7031, 2005.

[16] D. Wistuba, J. Kang, and V. Schurig, "Chiral separation by capillary electrochromatography using cyclodextrin phases," Methods in Molecular Biology, vol. 243, pp. 401-409, 2004. 
[17] V. Pino, A. W. Lantz, J. L. Anderson, A. Berthod, and D. W. Armstrong, "Theory and use of the pseudophase model in gasliquid chromatographic enantiomeric separations," Analytical Chemistry, vol. 78, no. 1, pp. 113-119, 2006.

[18] Q. Zhong, L. He, T. E. Beesley et al., "Development of dinitrophenylated cyclodextrin derivatives for enhanced enantiomeric separations by high-performance liquid chromatography," Journal of Chromatography A, vol. 1115, no. 1-2, pp. 19-45, 2006.

[19] M. Singh, R. Sharma, and U. C. Banerjee, "Biotechnological applications of cyclodextrins," Biotechnology Advances, vol. 20, no. 5-6, pp. 341-359, 2002.

[20] Q. Qi and W. Zimmermann, "Cyclodextrin glucanotransferase: from gene to applications," Applied Microbiology and Biotechnology, vol. 66, no. 5, pp. 475-485, 2005.

[21] N. A. F. Al-Rawashdeh, K. S. Al-Sadeh, and M. B. AlBitar, "Physicochemical study on microencapsulation of hydroxypropyl- $\beta$-cyclodextrin in dermal preparations," Drug Development and Industrial Pharmacy, vol. 36, no. 6, pp. 688-697, 2010.

[22] M. Motwani and J. Zatz, "Applications of cyclodextrins in skin products," Cosmetics \& Toiletries, vol. 112, pp. 39-47, 1997.

[23] E. Kurul and S. Hekimoglu, "Skin permeation of two different benzophenone derivatives from various vehicles," International Journal of Cosmetic Science, vol. 23, no. 4, pp. 211-218, 2001.

[24] S. Scalia, A. Casolari, A. Iaconinoto, and S. Simeoni, "Comparative studies of the influence of cyclodextrins on the stability of the sunscreen agent, 2-ethylhexyl-p-methoxycinnamate," Journal of Pharmaceutical and Biomedical Analysis, vol. 30, no. 4, pp. 1181-1189, 2002.

[25] K. B. Lipkowit, "Applications of computational chemistry to the Study of Cyclodextrins," Chemical Reviews, vol. 98, pp. 18291874, 1998.

[26] E. A. Castro and D. A. J. Barbiric, "Molecular modeling and cyclodextrins: a relationship strengthened by complexes," Current Organic Chemistry, vol. 10, no. 7, pp. 715-729, 2006.

[27] D. Thompson and J. A. Larsson, "Modeling competitive guest binding to $\beta$-cyclodextrin molecular printboards," Journal of Physical Chemistry B, vol. 110, no. 33, pp. 16640-16645, 2006.

[28] K. Harata, "The structure of the cyclodextrin complexes. XIII. Crystal structure of b cyclodextrin-1, 4-diazabicyclo[1. 2.2] octane complex tridecahydrate," Bulletin of the Chemical Society of Japan, vol. 55, pp. 2315-2320, 1982.

[29] S. Pattanaargson, T. Munhapol, P. Hirunsupachot, and P. Luangthongaram, "Photoisomerization of octyl methoxycinnamate," Journal of Photochemistry and Photobiology A, vol. 161, no. 2-3, pp. 269-274, 2004.

[30] S. Pattanaargson and P. Limphong, "Stability of octyl methoxycinnamate and identification of its photo-degradation product," International Journal of Cosmetic Science, vol. 23, no. 3, pp. 153-160, 2001.

[31] F. Trotta, M. Zanetti, and G. Camino, "Thermal degradation of cyclodextrins," Polymer Degradation and Stability, vol. 69, no. 3, pp. 373-379, 2000.

[32] F. Giordano, C. Novak, and J. R. Moyano, "Thermal analysis of cyclodextrins and their inclusion compounds," Thermochimica Acta, vol. 380, no. 2, pp. 123-151, 2001.

[33] S. Kohata, K. Jyodoi, and A. Ohyoshi, “Thermal decomposition of cyclodextrins $(\alpha-, \beta-, \gamma-$, and modified $\beta-\mathrm{CyD})$ and of metal$(\beta-\mathrm{CyD})$ complexes in the solid phase," Thermochimica Acta, vol. 217, pp. 187-198, 1993.
[34] M. K. Ghorab and M. C. Adeyeye, "Elucidation of solution state complexation in wet-granulated oven-dried ibuprofen and $\beta$-cyclodextrin: FT-IR and 1H-NMR studies," Pharmaceutical Development and Technology, vol. 6, no. 3, pp. 315-324, 2001.

[35] T. Loftsson and M. Masson, "Cyclodextrins in topical drug formulations: theory and practice," International Journal of Pharmaceutics, vol. 225, no. 1-2, pp. 15-30, 2001. 

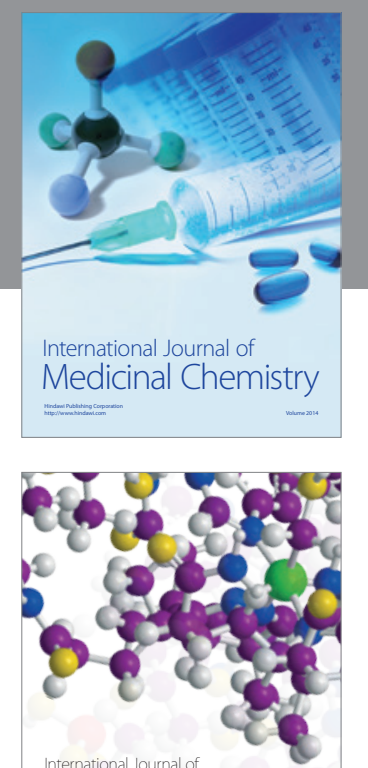

\section{Carbohydrate} Chemistry

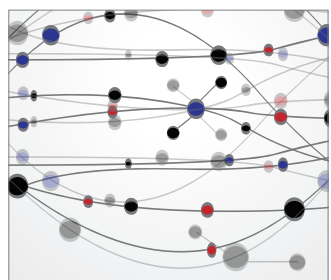

The Scientific World Journal
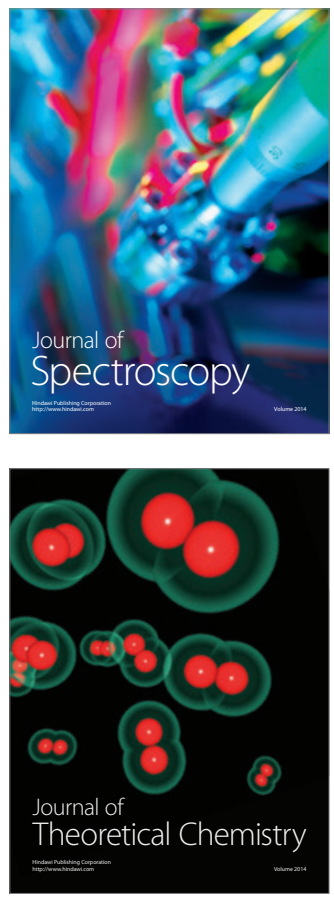
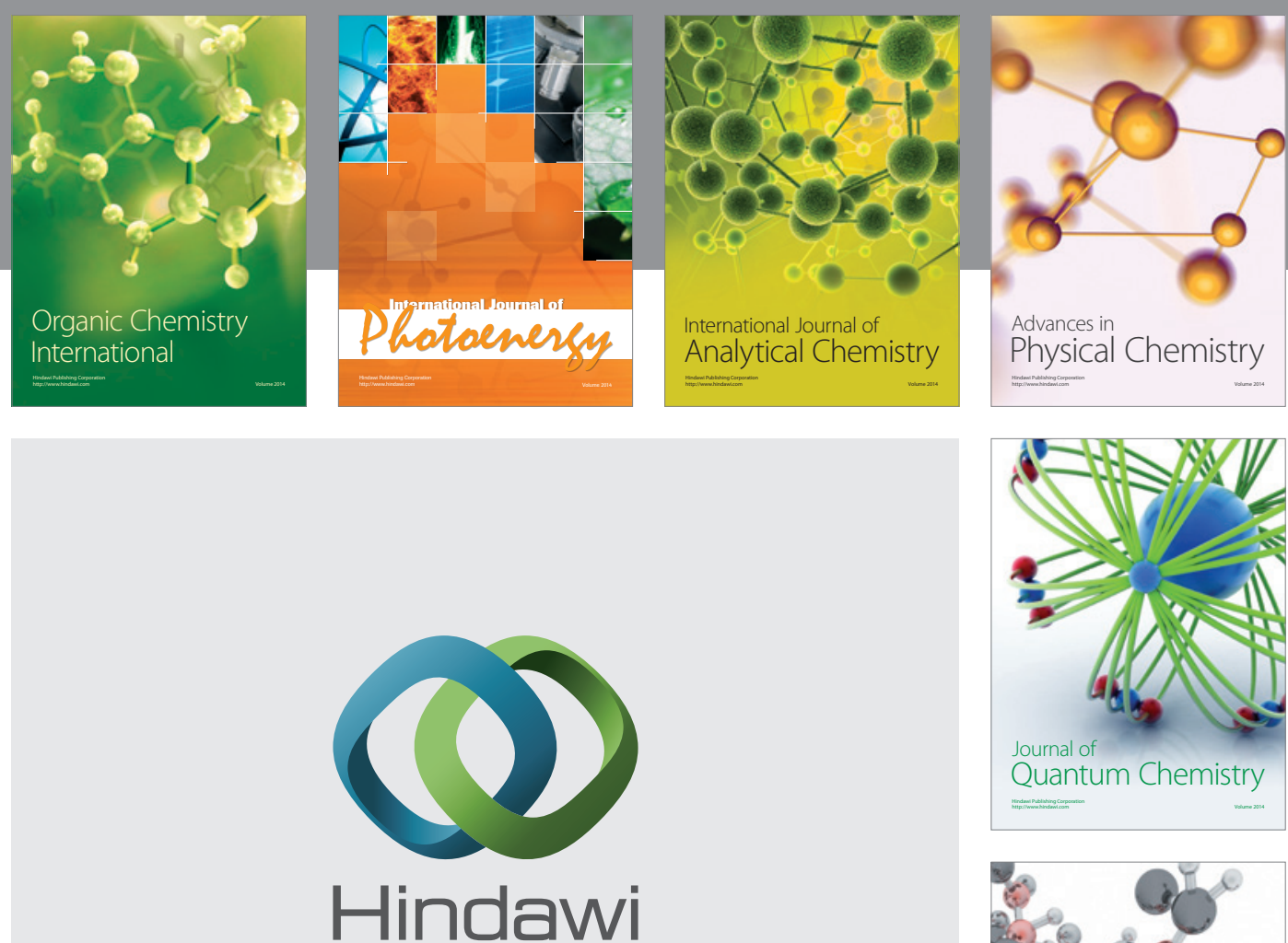

Submit your manuscripts at

http://www.hindawi.com

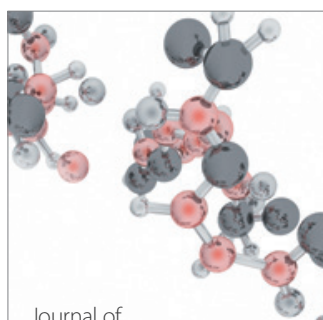

Analytical Methods

in Chemistry

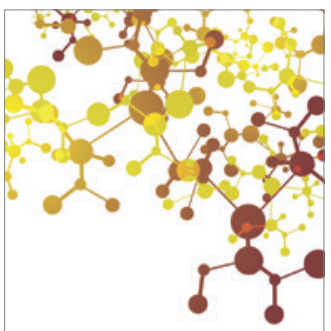

Journal of

Applied Chemistry

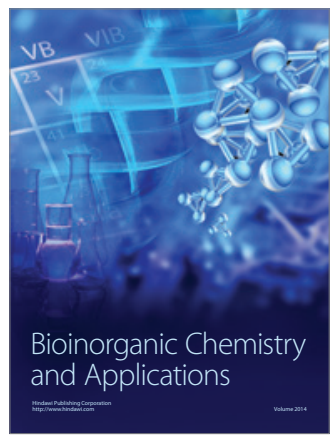

Inorganic Chemistry
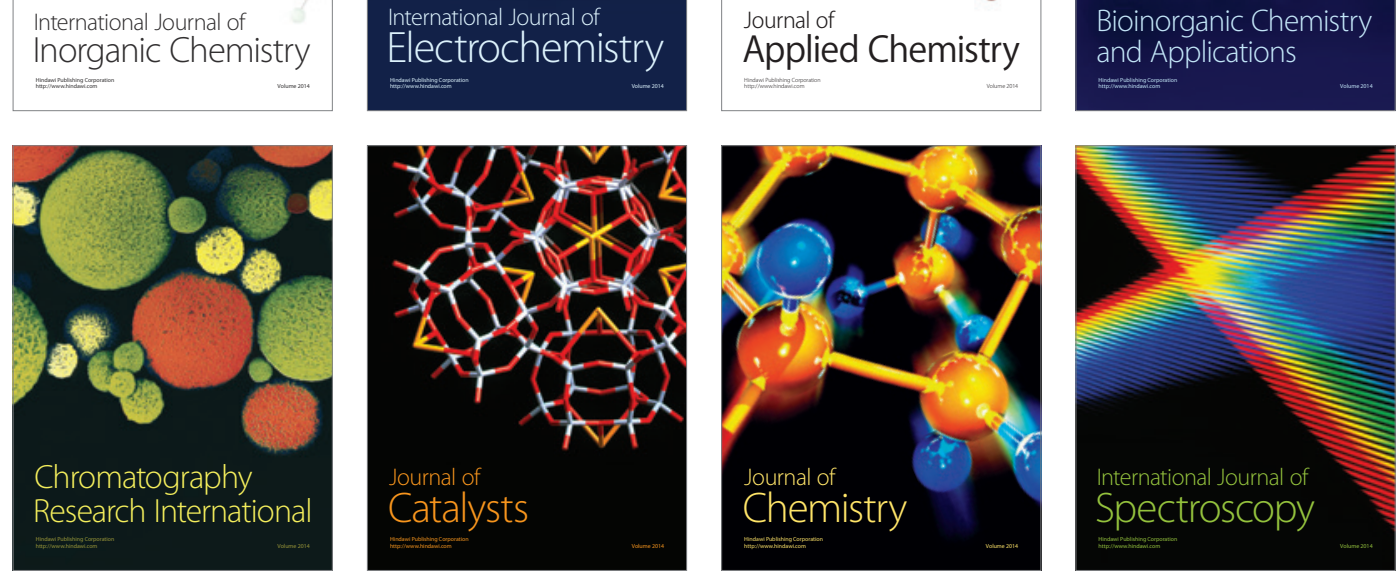